\title{
DIRETIVAS ANTECIPADAS DE VONTADE: O EXERCÍCIO DA AUTONOMIA EXISTENCIAL DO MENOR EM ESTADO TERMINAL
}

\section{ANTECIPATED DIRECTIVES OF WILL: THE EXERCISE OF EXISTENTIAL AUTONOMY OF THE DYING MINOR}

\author{
Jennifer Silveira Torquato ${ }^{1}$ \\ Mirelle Fernandes Soares ${ }^{2}$
}

RESUMO: O presente trabalho se propôs a analisar o exercício da autonomia existencial do paciente menor de idade para elaborar uma Diretiva Antecipada de Vontade, tendo como objetivo verificar a possibilidade de garantir que a vontade da criança e do adolescente em estado terminal seja concretizada. Para tanto, foi utilizado o método hipotético-dedutivo, com coleta de dados em doutrinas, revistas, artigos, legislação e jurisprudência sobre o tema.

Palavras-chave: Diretivas Antecipadas. Autonomia privada. Criança. Adolescente. Dignidade da pessoa humana.

ABSTRACT: The present work aimed to analyze the exercise of the existential autonomy of the underage patient to elaborate an Early Will Directive, with the objective of verifying the possibility of ensuring that the will of the terminally ill child and adolescent is realized. For this, the hypothetical-deductive method was used, with data collection in doctrines, journals, articles, legislation and jurisprudence on the subject.

Keywords: Advance Directives. Private Autonomy. Child. Teenager. Dignity of the human person.

\section{INTRODUÇÃO}

O direito, compreendido como fenômeno social, cultural e histórico, não se mantém à margem quando identifica problemas práticos que afetam a sociedade, especialmente no campo das ciências, saúde e das biotecnologias, cujas modernas descobertas se mostram aceleradas.

Ao novo campo do direito que foca no estudo e na normatização das questões bioéticas, convencionou-se chamar de biodireito e a importância de trazer o instituto das diretivas

\footnotetext{
${ }^{1}$ Graduada em Direito pela Faculdade Kennedy de Minas Gerais. Endereço eletrônico institucional: jennifer.torquato@soukennedy.com.br.

${ }^{2}$ Mestre em Direito pela Universidade Federal de Minas Gerais - UFMG. Professora de Direito Civil, Direito de família e sucessões, da Faculdade Kennedy de Minas Gerais. Sócia do escritório Fernandes Alves Advogados. Pesquisadora do PRUNART - UFMG (Programa Universitário de Apoio às Relações de Trabalho e à Administração da Justiça). Integrante das Comissões de Direito das sucessões e de Direito Sistêmico da OAB/MG. Advogada Militante com experiência em Direito de família, sucessões, previdenciário trabalhista e cível. Endereço eletrônico institucional: mirelle.soares@soukennedy.com.br.
} 
antecipadas ao debate está no fato de que a delineação de suas regras contribui para validar o respeito pela dignidade humana e pelas liberdades fundamentais.

O documento, que já se encontra incorporado em Ordenamentos Jurídicos de Países como Argentina e Uruguai, no Brasil tem como pressupostos a Resolução I805/2006, a Resolução 1995/2012, a Resolução 2232/2019 e o Código de Ética Médica, elaboradas pelo Conselho Federal de Medicina.

Muitas dúvidas e incertezas ainda rondam o tema, como o possível conflito entre o direito à vida e dignidade com o princípio da autonomia privada, contudo, baseando-se nas resoluções editadas pelo Conselho Federal de Medicina, os indivíduos maiores e capazes podem optar pela Ortotanásia, uma vez que tal prática não é vedada pelo ordenamento jurídico brasileiro e não fere os princípios gerais do direito, tendo como objetivo a busca pela humanização da morte de quem se encontra em situação irreversível, ao afastar tratamentos que não surtirão efeitos na enfermidade apresentada.

Nesse sentido, o presente artigo investiga se há espaço para a autodeterminação do menor que, acometido de doença terminal, se recuse a realizar as medidas terapêuticas indicadas pelo seu médico.

Objetivou-se analisar se seria possível a criança ou o adolescente que possuem o mínimo discernimento, recusar tratamentos que estejam lhe causando sofrimento, ainda que tal recusa lhes causasse a morte.

Para se chegar a uma reflexão coerente, o levantamento bibliográfico compreendeu pesquisas nas Resoluções do Conselho Federal de Medicina, em obras do ramo do Direito e Medicina e ainda em artigos de revistas científicas e jurisprudências.

Devido ao maior grau de vulnerabilidade das crianças e adolescentes, o trabalho se preocupou em demostrar como os princípios da proteção integral e do melhor interesse podem ser aplicados com vistas a garantir que diante de situações existenciais, que se mostrarem irreversíveis, que a vontade do menor também seja considerada, sobretudo, em decisões que dizem respeito à saúde e dignidade.

\section{REFERENCIAL TEÓRICO}

\section{I.I Diretivas Antecipadas De Vontade}

As Diretivas Antecipadas de Vontade (DAV), estão definidas no artigo I.ำ da resolução n.ํ 1.995/2012, do Conselho Federal de Medicina, sendo consideradas como "o conjunto de desejos, prévia e expressamente manifestados pelo paciente, sobre cuidados e tratamentos que quer, ou 
não, receber no momento em que estiver incapacitado de expressar, livre e autonomamente, sua vontade" (CONSELHO FEDERAL DE MEDICINA, 2012).

O instituto em epígrafe é considerado o gênero, que se subdivide em Testamento Vital e Mandato Duradouro ou procurador para cuidados de saúde, podendo o paciente, segundo Mabtum e Marchetto (2015, p.I4), fazer jus a ambos os instrumentos, de forma prévia, caso no futuro venha padecer de doença terminal ou incurável, em que seu quadro clínico seja irreversível.

De acordo com Nunes (2016, p.94), o Testamento Vital é o documento elaborado pelo paciente, com auxílio de seu médico, e deverá constar detalhadamente, os tratamentos que dispensa e os que aceita, nesse caso, o próprio paciente, gozando de sua sanidade, deixa registrado o seu desejo, que será atendido em momento que não puder mais se expressar.

No ensinamento de Lippmann (2013, p.17), o testamento vital é uma declaração escrita, na qual o paciente registra sua vontade quanto aos tratamentos aos quais não deseja ser submetido, caso esteja impossibilitado de se manifestar e não deve ser confundido com o testamento civil, uma vez que este trata de bens patrimoniais e aquele de bens existenciais.

Dessa maneira, pode ser considerado um instrumento que oportuniza o registro da vontade de uma pessoa, de como deve ser tratada diante de uma enfermidade, deixando registrado as terapias que deseja e as que não deseja receber, caso sobrevenha uma impossibilidade se se manifestar.

O Mandato Duradouro ou procurador para cuidados de saúde, também pode ser elaborado pelo paciente com o auxílio de um médico, porém, de acordo com Penalva (2009, p.55), não deve ser confundido com o Testamento Vital, ao passo que se resume a nomear um procurador, pessoa de confiança, que decidirá em nome do paciente, no momento em que houver uma impossibilidade de fazê-lo pessoalmente.

Para Godinho (2012, p.24), o mandato duradouro pressupõe a constituição de um mandatário, que se encarrega de agir de acordo com as instruções recebidas pelo paciente, atuando como interlocutor entre este e a equipe médica, de forma que as instruções recebidas devem ser fielmente empregadas.

Assim, entende-se que o instituto do mandato duradouro, garante a escolha de uma pessoa para acompanhar os procedimentos médicos para que a vontade do paciente seja integralmente atendida.

Entende-se que ambas as espécies de Diretivas Antecipadas de Vontade, tem por objetivo viabilizar a manifestação da vontade do paciente acometido de doença grave ou incurável, utilizando tais instrumentos para assegurar que a vontade manifestada seja respeitada. 


\subsection{Histórico e evolução das Diretivas Antecipadas de Vontade}

Conhecidas pela expressão living will, as Diretivas Antecipadas de Vontade tiveram sua origem na década de 1960, em solo estadunidense, local em que de acordo com Mabtum e Marchetto (2015, p.o6), foram estabelecidas as regras e limites de aplicação.

A evolução das diretivas, contou com a grande colaboração de Louis Kutner, um advogado que em 1969, conforme demonstra Penalva (2008, p.05), propôs um novo modelo de documento, mais completo, o qual se referia às prévias decisões de pacientes que se encontravam em estado de terminalidade.

No entanto, conforme preconiza Dadalto (2020, p.65), foi no ano de 1967 , através da Sociedade Americana para a Eutanásia (SAE), que a primeira lei referente ao instituto foi aprovada, no Estado da Califórnia, garantindo a possibilidade de uma pessoa recusar tratamentos, e atribuindo segurança aos profissionais de saúde, em caso de eventuais processos, por terem seguido a vontade descrita pelo paciente em suas diretivas.

Além da evolução em solo americano, as Diretivas se expandiram para solo europeu, local em que, no ano de 1997, conforme Jiménez (1997, p.o2), foi firmado o Convênio de Oviedo, para a Proteção dos Direitos Humanos e da Dignidade do ser Humano, com respeito às aplicações da biologia e da medicina, trazendo um novo panorama mundial, por se tratar da primeira norma internacional a respeito do tema.

Contudo, Dadalto (2020, p.70) afirma que, a despeito de o Convênio ter sido ratificado por 23 dos 47 Estados-Membros, à época, foi em 2002 que os países começaram a legislar sobre o tema, com exceção da Finlândia, Holanda e Hungria, que já possuíam legislação vigente sobre as Diretivas Antecipadas de Vontade.

$\mathrm{Na}$ América Latina, Porto Rico, através da lei no 160/200I, foi pioneiro no que se refere a legislação sobre as Diretivas Antecipadas de Vontade, como aponta Donida (2016, p.85), conferindo autonomia e garantindo aos maiores e capazes o registro de suas Diretivas.

Em se tratando da América do Sul, países como Argentina e Uruguai, contam com legislação sobre o tema. Na Argentina, apesar da lei sobre as Diretivas ter sido aprovada apenas em 2009, Coninck (2017, p.105) afirma que o país já contava com vasto entendimento referente ao assunto, contando, inclusive, com uma lei da província de Rio Negro, promulgada em 2007 e considerada a primeira lei argentina a tratar de forma específica sobre as Diretivas Antecipadas.

No Uruguai, a lei 18.473, que regulamenta a utilização das Diretivas, está em vigor desde 2009 e conforme afirma Ehle e Rodrigues (2016, p.15) dispõe acerca de tratamentos e procedimentos médicos que podem ser dispensados, por não contribuírem substancialmente na qualidade de vida 
de pacientes que enfrentam patologia terminal ou incurável, preocupando-se ainda em afirmar a autonomia dos cidadãos para deliberar sobre o que deverá ser feito ao fim de suas vidas.

No Brasil, o instituto é relativamente novo e ainda não conta com legislação, todavia, as Resoluções editadas pelo Conselho Federal de Medicina buscam uniformizar a prática, propondo maior atenção ao tema, conforme será explanado no capítulo seguinte.

\section{I.3 Validade das Diretivas Antecipadas de Vontade no ordenamento jurídico brasileiro}

\subsection{Resolução 1.805/2006 Conselho Federal de Medicina}

Em 28 de novembro de 2006, o Conselho Federal de Medicina editou a Resolução n. o I.805/o6 que conforme Dadalto (2020, p.95), dispõe sobre o agir do médico diante do pedido do enfermo ou de seu representante para que sejam limitados ou suspensos os tratamentos em caso de o paciente se encontrar em estado terminal, grave ou incurável.

No entanto, apesar de prever tal possibilidade, o artigo 2.ㅇ (CONSELHO FEDERAL DE MEDICINA, 2006) esclarece que os tratamentos que tem o objetivo de atenuar o sofrimento, devem ser assegurados integralmente, garantindo assim, os meios necessários para que o paciente possa ter conforto em seus últimos dias de vida, podendo, inclusive, fazer jus a alta hospitalar, caso essa seja a sua vontade.

A resolução em questão trata exatamente da prática denominada como ortotanásia, conhecida por Cardoso (2010, p.206) como o processo natural da morte, que se apresenta como o respeito ao bem-estar do indivíduo e não deve ser confundida com a eutanásia, uma vez que a primeira se dispõe a permitir que a morte aconteça sem que haja qualquer intervenção artificial, já na segunda há a utilização de meios artificiais que visam acelerar o processo morte.

A resolução em comento foi alvo da Ação Civil Pública nº.007.34.00.0148093 (2010, p. 02), proposta pelo Ministério Público Federal em face do Conselho Federal de Medicina, que pleiteou a nulidade ou alteração dos termos da resolução, sob o argumento de que o Conselho Federal de Medicina não possui o poder de regulamentar como ética, uma conduta tipificada como crime, apresentando como justificativa a indisponibilidade do direito à vida.

No entanto, o magistrado Federal Roberto Luiz Luchi Demo, além de demonstrar as diferenças entre os institutos da Eutanásia e ortotanásia, sanando a confusão feita pelo Ministério Público, ponderou que se trata de matéria extremamente polêmica, sobretudo para os padrões culturais do Brasil.

Assim, no ano de 2oro, tanto o pedido de nulidade quanto o pedido de alteração do documento foram rejeitados, restando reconhecida a legitimidade da Resolução, bem como do 
Conselho Federal de Medicina por sua edição, vez que, conforme registrado na sentença (BRASIL, AÇÃO CIVIL PÚBLICA no..007.34.00.0148093, 2010, p.14), considerou que a ortotanásia não é crime tipificado pelo código penal, e ainda, que o direito à boa morte decorre diretamente do princípio da dignidade da pessoa humana.

Assim, ficou reconhecido que o Conselho Federal de Medicina agiu exatamente de acordo com sua competência, uma vez que a presente Resolução não contraria as leis vigentes, buscando com o documento, resguardar a conduta médica, em casos que o paciente manifeste seu interesse em suspender os tratamentos.

\subsubsection{Resolução 1.995/2012 e 2.232/2019 do Conselho Federal de Medicina}

Outro notável documento, também editado pelo Conselho Federal de Medicina, foi a Resolução n. ${ }^{\text {O }}$ 1995, de 31 de agosto de 2012, dando início a uma discussão mais aprofundada sobre o instituto das Diretivas Antecipadas de Vontade, pois de acordo com Dadalto (2020, p.99), foi o primeiro documento a regulamentar especificamente o tema, no âmbito da conduta médica.

Dentre as exposições de motivos, o Conselho Federal de Medicina destaca a necessidade de disciplinar a conduta médica, considerando ainda a crescente relevância da autonomia atribuída ao paciente, que conforme o artigo 2으 (CONSELHO FEDERAL DE MEDICINA, 2012), só não será considerada quando se confrontar com os preceitos previstos no código de Ética Médica.

A Resolução em comento avançou sobremaneira o processo de respeito a autonomia do paciente, conforme ensina Pereira (2018, p.36), uma vez que, delimitou fatores importantes, demonstrando que apesar dos novos recursos que buscam prolongar a vida serem benéficos em alguns casos, podem, por outro lado contribuir negativamente, ao prolongar o sofrimento de pacientes em estado terminal.

Seguindo a mesma tendência da Resolução r.995/2012, o Conselho Federal de Medicina editou a resolução 2.232, em I6 de setembro de 2019, estabelecendo normas éticas para a recusa de terapias por pacientes, e dentre as justificativas apresentou o fato de a Constituição incluir a dignidade da pessoa humana como um dos fundamentos da República, dispondo em seu artigo 2. que "é assegurado ao paciente maior de idade, capaz, lúcido, orientado e consciente, o direito de recusa à terapêutica proposta em tratamento eletivo, de acordo com a legislação vigente" (CONSELHO FEDERAL DE MEDICINA, 2019).

Nesse sentido, já é possível encontrar no direito brasileiro casos que trazem decisões fundamentadas também com base nas resoluções do órgão, nesse sentido o julgado a seguir, considerou a resolução I.995/2012 para fundamentar a decisão. 
AGRAVO DE INSTRUMENTO. DIREITO À SAÚDE. AUTORIZAÇÃO PARA REALIZAÇÃO DE PROCEDIMENTO CIRÚRGICO. NEGATIVA DO PACIENTE. NECESSIDADE DE SER RESPEITADA A VONTADE DO PACIENTE. I. O direito à vida previsto no artigo 5.․ da Constituição Federal não é absoluto, razão por que ninguém pode ser obrigado a se submeter a tratamento médico ou intervenção cirúrgica contra a sua vontade, não cabendo ao Poder Judiciário intervir contra esta decisão, mesmo para assegurar direito garantido constitucionalmente. 2. Ademais, considerando que "não se justifica prolongar um sofrimento desnecessário, em detrimento à qualidade de vida do ser humano", o Conselho Federal de Medicina, publicou a Resolução n.o r.995/2012, ao efeito de dispor sobre as diretivas antecipadas de vontade do paciente, devendo sempre ser considerada a sua autonomia no contexto da relação médico-paciente [...] (Agravo de Instrumento n.o 70065995078 , Primeira Câmara Cível, Tribunal de Justiça do Rio Grande do Sul, Relator: Ser gio Luiz Grassi Beck, julgado em 03 de setembro de 2015).

Observa-se, ao analisar a decisão acima, que houve a prevalência da autonomia do paciente em face do direito à vida, pois conforme explicado pelo relator, este não é absoluto. A decisão consagrou ainda, a autonomia do paciente para recusar a intervenção cirúrgica, fundamentandose com base na resolução do Conselho Federal de Medicina, uma vez que não se admite prolongar o sofrimento daqueles que se encontrem fora das possibilidades de cura.

Assim, tanto a resolução I.995/2012 quanto a resolução 2.232/2019, tem como objetivos além de disciplinar a conduta médica e estabelecer normas éticas, buscar o fim da utilização de terapias desmedidas, respeitando a dignidade e autonomia do paciente.

\subsubsection{Código de Ética Médica/ Resolução 2.217/2018}

O código de ética médica é igualmente importante quando o assunto são as Diretivas Antecipadas de Vontade, pois além de estabelecer princípios que regulam a conduta profissional, seu objetivo se coaduna com os demais documentos do órgão, visando que os profissionais da área da saúde priorizem a autonomia do paciente.

Inicialmente o código de Ética Médica foi previsto na Resolução I.931 de 2009, hoje revogada. O diploma normativo, ainda que tenha sofrido modificações através da resolução 2.217 de 2018 , manteve intacta em seu artigo 4I as disposições acerca da vontade do paciente ou de seu representante legal, que demonstra a relevância da manutenção dos cuidados Paliativos, além de prever em seu bojo, tanto o Testamento Vital quanto o Mandato Duradouro, ambas, espécies de Diretiva Antecipada de Vontade, conforme já mencionado.

Artigo 4I. Nos casos de doença incurável e terminal, deve o médico oferecer todos os cuidados paliativos disponíveis sem empreender ações diagnósticas ou terapêuticas inúteis, ou obstinadas, levando sempre em consideração a vontade 
expressa do paciente ou, na sua impossibilidade, a de seu representante legal (CÓDIGO DE ÉTICA MÉDICA, 2018).

Depreende-se do artigo citado, que o novo Código de Ética Médica, a despeito das recentes modificações, permanece alinhado às outras Resoluções editadas pelo Conselho Federal de Medicina, demonstrando que o médico vem assumindo o papel de orientador, sem que seja necessário dispor de cuidados essenciais à manutenção da dignidade do paciente.

Nessa perspectiva, considerando o contexto geral das resoluções acima tratadas, ao ponderar sobre a Ação Civil proposta pelo Ministério Público, a primeira vista, pode-se concluir, que a regulamentação por meio do Conselho Federal de Medicina, no que concerne as Diretivas Antecipadas de Vontade, não foi bem aceita no meio jurídico.

No entanto, ainda que tais resoluções sejam vinculantes somente entre os profissionais da área médica, o Conselho Federal de Medicina se mostra um passo à frente do Poder Legislativo, de forma que, para que o Brasil se alinhe definitivamente às novas tendências, perdura a necessidade de suprir a carência legislativa referente ao tema, com o escopo de aumentar a segurança jurídica e consequentemente reduzir as possibilidades de interpretações equivocadas.

\section{I.4 Projetos de lei sobre as Diretivas Antecipadas}

Muito embora as Resoluções estudadas no capítulo anterior sejam um marco no processo de evolução da busca pela humanização da morte, em consonância com os princípios que integram o ordenamento jurídico, a carência legislativa no contexto Federal ainda prevalece quando se trata das Diretivas Antecipadas de vontade.

Não obstante, com a finalidade de se obter respostas aos diversos questionamentos e sanar a insegurança jurídica que ainda permeia o tema, alguns projetos de lei foram propostos, estando um deles ainda em tramitação no Senado Federal.

Trata-se do projeto de lei no 149 (2018), que apresenta como justificação a intensa evolução tecnológica no campo médico, e também pela necessidade de inserir o Brasil no contexto mundial em que estão os países mais desenvolvidos, com o intuito de garantir ao paciente o poder decisório na dispensa de tratamentos que sejam inúteis à manutenção da vida de maneira digna.

Um ponto do projeto que chama a atenção e de suma relevância, sobretudo ao presente estudo, refere-se ao conteúdo previsto em seu artigo terceiro, ao dispor que, "toda pessoa maior e capaz tem o direito de declarar a sua vontade de receber ou não determinados tratamentos médicos" (BRASIL, PROJETO DE LEI I49, 2018), contudo, em análise da Comissão de Assuntos Sociais e diante da aprovação do projeto, o artigo ı.o, § ı. o do Substitutivo do Projeto de Lei 
149/2018, definiu que "o maior de 16 (dezesseis) anos e menor de 18 (dezoito) anos poderá manifestar sua vontade, mediante autorização judicial e através de verificação de seu discernimento por meio de assistente psicossocial” (BRASIL, PROJETO DE LEI I49, 2018).

Além do projeto descrito acima, foi apresentado também em 2018 o Projeto de Lei 267, que trazia em seu bojo um texto similar ao do projeto citado anteriormente, justificando a propositura, nos termos do projeto (2018), pelo déficit legislativo e pelo anseio em tornar reconhecida a autonomia do paciente em fim de vida. Contudo, conforme consta no site do Senado Federal, o projeto foi retirado pelo autor, com posterior arquivamento do mesmo.

Nesse sentido, há de se reconhecer a lacuna legislativa no que diz respeito ao tema, contudo, conforme já demonstrado, as resoluções editadas pelo Conselho Federal de Medicina, ainda que aplicadas como diretrizes orientadoras da conduta médica, podem servir, inclusive, como parâmetro para orientar os operadores do direito.

\subsection{Cuidados paliativos}

Os cuidados paliativos, previstos no artigo 4I do Código de Ética Médica e ainda no artigo $2^{-}$- da Resolução r.805 do Conselho Federal De Medicina, podem ser vistos sob o prisma de que o processo morte não deve ser encarado como sinônimo de dor, e sim com vistas a garantir ao enfermo medidas que vislumbrem o seu bem-estar em fim de vida.

De acordo com o conceito apresentado pela Organização Mundial de Saúde (OMS), "Cuidado Paliativo é uma abordagem que promove qualidade de vida aos pacientes que enfrentam doenças que ameaçam a continuidade da vida, através da prevenção e alívio do sofrimento" (ORGANIZAÇÃO MUNDIAL DA SAÚDE apud MATSUMOTO, 2oro, p.26).

Segundo Penalva (2009, p.99), são considerados cuidados paliativos, os tratamentos e cuidados que garantem ao paciente a manutenção de sua qualidade de vida, até o momento de sua morte.

No ensinamento de França (2014, p.554), apesar dos desenvolvimentos substanciais da medicina e com o aumento das possibilidades de prolongar a vida, a utilização inadequada de tratamentos, apenas com o propósito de estender a existência, deve ser questionado, uma vez que além de a medicina ter o compromisso de curar, carrega também o dever de oferecer uma vivência respeitosa, minorando o sofrimento e aliviando o desconforto de pacientes terminais.

Dessa forma, os cuidados paliativos podem ser classificados como uma forma de assistir ao paciente quando a terapia curativa deixar de alcançar os objetivos esperados, e ainda diante de situações em que, apesar de haver como retardar os sintomas da doença, se o paciente manifestar 
seu desejo de não prosseguir com os tratamentos, a atenção deve ser voltada para aliviar a dor e o sofrimento e não mais para a cura.

\subsection{Direito à morte digna}

A vida humana encontra proteção na Constituição de 1988, dispondo em seu artigo 5. , caput, sobre sua inviolabilidade. De acordo com Bermejo e Belda (2015, p.40) trata-se de um bem básico, mas não absoluto, uma vez que pertence a um ser limitado, devendo a inviolabilidade do direito à vida ser entendida como o direito que cada um tem de estar vivo, sem que haja violações ou atentados que vão de encontro com a existência do indivíduo.

Dentre os critérios fundamentais, previstos para garantir o direito à vida, e a dignidade da pessoa humana, o artigo $5^{\circ}$, III da Constituição Federal de 1988, destaca que "ninguém será submetido a tortura nem a tratamento desumano ou degradante" (BRASIL,1988).

Assim, seguindo a perspectiva do artigo em análise, obrigar que sejam ministrados tratamentos ineficazes às pessoas que se encontrem em situação de terminalidade, soa um tanto contraditório, uma vez que, conforme destacado por Provin e Garcia (2013, p.12) o prolongamento artificial da vida, através de aparelhos ou medicamentos pode ser considerado mais desumano, ou degradante do que a própria morte.

Nesse sentido, o respeito pela dignidade exige o reconhecimento de que algumas medidas apenas protraem a vida, sem que apresente qualquer benefício, e assim como o direito à vida é amparado pelo princípio da dignidade da pessoa humana, o direito à morte também carece de tal amparo, uma vez que manter alguém vivo sem que exista qualquer perspectiva substancial de cura, caso haja manifestação do paciente no sentido de cessar a terapia, não condiz com a realidade atual do ordenamento jurídico pátrio, que mantém relação direta com a dignidade da pessoa humana.

\section{RESULTADOS E DISCUSSÕES}

\section{I A criança e o adolescente como sujeitos de direitos e o princípio do melhor interesse}

Historicamente, os interesses de crianças e adolescentes eram integralmente administrados pelos seus responsáveis, assim, qualquer forma de autonomia lhes era negada, sendo, o reconhecimento como detentores de direitos e garantias, encarado sob o enfoque de uma realidade ainda recente.

O tratamento direcionado à criança e ao adolescente, segundo Lima; Poli; José (2017, p. o6/o8), pode ser delimitado em três fases distintas: na primeira delas eram considerados como 
seres irrelevantes e sem personalidade, na segunda como objeto de tutela do Estado, e finalmente, na terceira fase, que se estende até os tempos atuais, passaram a ser notados como seres que necessitam de amparo prioritário e integral.

Nesse sentido, o ano de 1959 é emblemático no que se refere ao avanço dos direitos das crianças e adolescentes, uma vez que em 20 de novembro de 1959, foi proclamada pelas Nações Unidas, a Declaração dos Direitos da Criança, reafirmando a necessidade de "assistência especial" (DECLARAÇÃO DOS DIREITOS DA CRIANÇA, 1959), antes prevista no artigo 25 da Declaração Universal de Direitos Humanos (1948).

Em esfera nacional, a Constituição da República Federativa do Brasil, Promulgada no ano de 1988 , com influência dos documentos internacionais, estabeleceu mudanças significativas, ao inserir no texto constitucional o princípio da proteção absoluta, conforme destaca Marques (20II, p.54), uma vez que, devido à condição de seres em desenvolvimento, necessitam de tratamento especial.

Assim, o artigo 227 da Carta Magna estabelece que:

Artigo 227. É dever da família, da sociedade e do Estado assegurar à criança, ao adolescente e ao jovem, com absoluta prioridade, o direito à vida, à saúde, à alimentação, à educação, ao lazer, à profissionalização, à cultura, à dignidade, ao respeito, à liberdade e à convivência familiar e comunitária, além de colocá-los a salvo de toda forma de negligência, discriminação, exploração, violência, crueldade e opressão (BRASIL, 1988).

Observa-se que o artigo em questão atribui um esforço conjunto de todos os envolvidos, que prescreve a adoção de uma série de medidas que tenham como objetivo, a concretização prioritária dos direitos elencados, devido ao caráter especial atribuído aos menores pelos documentos internacionais e posteriormente adotado pela Constituição.

Logo após o advento da Carta Magna, o Estatuto da Criança e do adolescente (ECA), promulgado pela lei 8.069 em 1990, trouxe uma gama de princípios e regras que regem a vida de crianças e adolescentes, até que estes atinjam a maioridade.

O artigo primeiro do Estatuto, (Lei n. 9 8.069, de 13 de julho de 199o), seguindo o modelo constitucional, consagrou o princípio da proteção integral, que está diretamente ligado ao princípio do melhor interesse, de forma que este "traduz a ideia de que, na análise do caso concreto, os aplicadores do direito devem buscar a solução que proporcione maior benefício possível para a criança ou adolescente" (BARROS, 2018, p.23).

Seguindo o entendimento explicitado acima, pode-se compreender que na senda do arcabouço jurídico construído em torno dos direitos das crianças e dos adolescentes, toda e 
qualquer norma ou princípio, deve ser interpretado de acordo com a necessidade primeira dos mesmos.

Assim, ao remontar o contexto de surgimento e evolução dos direitos da criança e do adolescente, os documentos nacionais e internacionais se destacam como primordiais para garantir que as necessidades destes sejam atendidas, de forma a direcionar os princípios constitucionais e aquele previsto no Estatuto da Criança e do Adolescente, sempre com vistas a afirmar a posição de tais indivíduos como detentores de direitos e garantias fundamentais.

\subsection{Autonomia privada e progressiva do menor}

O que fundamenta o direito da pessoa de elaborar uma diretiva antecipada de vontade é o poder que esta tem de se autodeterminar, assim, o conceito de autonomia, no ensinamento de Travessoni (2009, p.16I), tem intrínseca ligação à noção de liberdade, ao entender o discernimento como fundamento suficiente da determinação de vontade, tornando-a autora e conteúdo da legislação.

A autonomia privada reconhece tanto os negócios jurídicos de cunho patrimonial quanto os de natureza existencial, assim é o entendimento de Farias e Rosenvald sobre o tema:

\footnotetext{
A Autonomia privada transcende o perímetro dos negócios jurídicos patrimoniais, pois, em uma ordem pós-positivista, afirma-se como um exercício de liberdade e instrumento de concretização do princípio da dignidade da pessoa humana. Quer dizer, autonomia privada não se reduza ao espaço normativo em que o sujeito realiza atividade econômica, sendo também localizada sempre que o ser humano manifesta situações jurídicas da personalidade, concretizando seus projetos espirituais. Aqui, afirma-se a autonomia existencial (FARIAS; ROSENVALD, 2016, p. 157).
}

Verifica-se que além dos negócios que envolvam situações contratuais ou obrigacionais, é possível afirmar ainda que, ao relacionar a autonomia privada ao princípio da dignidade da pessoa humana, o indivíduo passa a contar com a possibilidade de decidir sobre seu destino, de acordo com sua vontade.

Os direitos existenciais, na concepção de Cabral (2018, p.7o), devem ser definidos como aqueles inerentes à personalidade do ser humano. Dessa forma, situações que dizem respeito ao direito de morrer, por exemplo, são tratados na seara da autonomia existencial.

Assim, sendo os direitos existenciais, características inerentes ao ser humano, e ainda, devido a sua estreita relação com a dignidade da pessoa humana, decerto que em se tratando da autonomia da criança e do adolescente, estes não constituem exceção quando o assunto é a individualidade. 
Nesse cenário, as particularidades do indivíduo menor de idade, sobretudo, no plano das questões existenciais, requerem uma análise meticulosa, de forma que sejam verdadeiramente considerados como prioridade, interpretando os princípios da proteção integral e do melhor interesse em consonância ao princípio da dignidade da pessoa humana, não se admitindo que, direitos considerados personalíssimos sejam decididos apenas com base em decisões que se inclinam a violar a identidade do paciente.

\section{3 $\mathrm{O}$ poder familiar e suas limitações}

A questão da autonomia da criança e do adolescente encontra íntima ligação ao modo como o relacionamento familiar tem evoluído ao longo dos anos, uma vez que reconhecida progressivamente a possibilidade de se autodeterminarem, inclusive, no contexto familiar no qual se encontram.

No entanto, em uma realidade não muito distante, conforme expõe Dias (2015, p.165), imperava o chamado pátrio poder, no qual os filhos tinham a obrigação irrestrita de se sujeitarem aos pais, sobretudo ao homem, ao qual era atribuída a atuação como representante absoluto da família.

Com o movimento constitucionalista, as relações familiares ganharam novos contornos, que no entendimento de Moraes (2016, p. 209 apud LINS, 2017, p. 18), desenvolve um modelo cada vez mais democrático e plural, no qual o objetivo principal é manter uma relação de diálogo e de reciprocidade entre pais e filhos.

Nessa perspectiva, o artigo 1.630 do Código Civil de 2002, ao prever que "os filhos estão sujeitos ao poder familiar, enquanto menores" (BRASIL, 2002), deve ser interpretado não mais com base em um modelo autoritário de família e sim como o meio pelo qual a autoridade parental se compromete com o desenvolvimento da criança e do adolescente.

Dessa forma, por mais que seja compreensível a vulnerabilidade que acompanha o indivíduo até a fase adulta, o que torna indispensável a participação familiar nas decisões que dizem respeito aos menores, em determinadas situações, sobretudo em decisões que dizem respeito a direitos existenciais, há uma demanda para que a tomada de decisões seja feita em conjunto, de forma que, a personalidade dos filhos, seja desenvolvida com base no respeito à dignidade destes, levando ainda em consideração, a legítima necessidade da criança e do adolescente.

\subsection{Capacidade e discernimento da criança e do adolescente para elaborar uma Diretiva Antecipada de Vontade}


O código civil, em seu artigo $2^{\circ}$ estabelece que toda pessoa ao nascer com vida, adquire personalidade civil (Brasil, 2002), que de acordo com Gonçalves (2017, p.96) pode ser definida como a possibilidade de adquirir direitos e contrair obrigações, tendo intrínseca relação com a capacidade de direito ou de gozo, que é atribuída a todo e qualquer ser humano.

Contudo, embora seja atribuída a todo ser humano a titularidade de direitos e deveres, "nem todos possuem capacidade de fato ou exercício, caracterizada pela aptidão de atuar em nome próprio ao exercer os atos da vida civil” (NADER, 2018, p.216).

A capacidade plena, no que lhe concerne, se diferencia das demais, uma vez que, conforme ensinamento de Gagliano e Filho (2017, p.176) trata-se da reunião de ambas as espécies de

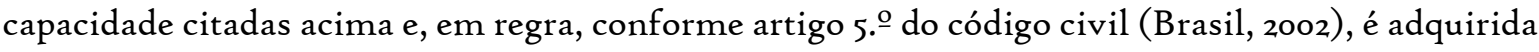
com o advento da maioridade, aos I8 (dezoito) anos, ou através das outras hipóteses previstas no referido artigo, as quais não são objetos deste estudo.

Assim, de acordo com o artigo 3. do código civil, "são absolutamente incapazes de exercer pessoalmente os atos da vida civil os menores de i6 (dezesseis) anos" (BRASIL, 2002), e conforme previsão do artigo 4.ำ, I do referido código, "são incapazes, relativamente a certos atos ou à maneira de os exercer: I - os maiores de dezesseis e menores de dezoito anos" (BRASIL, 2002).

Devido a pouca idade, o tratamento jurídico dispensado aos menores de i8 (dezoito) anos, diferem daquele atribuído aos plenamente capazes, uma vez que, por carregarem a característica da vulnerabilidade, a norma civil atribui a necessidade de uma proteção especial.

Nesse sentido, Madaleno (2017, p.92) explica que a especial proteção é justificável, pois devido à condição de maior vulnerabilidade e ainda por serem pessoas em desenvolvimento, necessitam de um regime especial de garantias.

Contudo, apesar da preocupação com a capacidade da pessoa que irá elaborar uma Diretiva Antecipada de Vontade, importa considerar não apenas o sistema civil de incapacidades, e sim fazer uma releitura deste sistema também com base no discernimento do paciente, pois, conforme ensinado por Teixeira e Konder (2008, p.73), não se deve permitir que a vulnerabilidade sirva para aprisionar o menor, como ocorre com o conceito tradicional de incapacidade.

Nesse sentido, o enunciado n. ${ }^{\mathrm{o}} \mathrm{I} 8 \mathrm{do}$ Conselho da Justiça Federal, aprovado na III Jornada de Direito Civil, entendeu que "a vontade dos absolutamente incapazes, na hipótese do inc. I do art. 3. ${ }^{\circ}$, é juridicamente relevante na concretização de situações existenciais a eles concernentes, desde que demonstrem discernimento bastante para tanto" (CJF, 2012, p.36).

Verifica-se com tal afirmação, que além de certa autonomia já atribuída aos maiores de i6 (dezesseis) anos e menores de 18 (dezoito anos) anos, considerados relativamente incapazes, o 
Conselho se preocupou em estender essa autonomia, no que diz respeito a questões existenciais, também aos absolutamente incapazes, devendo em ambos os casos, ser observado o grau de discernimento, ou seja, a capacidade de decidir.

Assim, de acordo com Beauchamp e Childress (2002, p.156 apud DADALTO, p.27), o paciente considerado capaz de decidir, é aquele que entende seu estado e faz um julgamento baseado em seus próprios valores, vislumbrando um determinado resultado e comunicando seu desejo àqueles que procuram saber qual a sua real vontade.

Conforme contexto apresentado, observa-se que a capacidade de discernimento se apresenta como um requisito primordial para validar a vontade manifestada pelo paciente e ainda, conforme ensina Dadalto (2020, p.28), a capacidade civil no que diz respeito às questões existenciais, é considerada como formalidade, pois no momento em que o paciente prestar seu consentimento, o que deve ser verificado é se este gozava de suas funções cognitivas e não se se enquadrava no conceito de pessoa capaz civilmente.

Destaca-se ainda a Resolução 4I, de 13 de outubro de 1995 do Conselho Nacional dos Direitos da Criança e do Adolescente (CONANDA), ao dispor em seu item I2, que "a criança e o adolescente têm o direito a não ser objeto de ensaio clínico, provas diagnósticas e terapêuticas, sem o consentimento informado de seus pais ou responsáveis e o seu próprio, quando tiver discernimento para tal" (CONSELHO NACIONAL DOS DIREITOS DA CRIANÇA E DO ADOLESCENTE, 1995).

Assim, a partir das discussões apresentadas, observa-se que as Resoluções do Conselho Federal de Medicina foram estabelecidas em consonância com a lei civil, permitindo aos maiores e capazes a elaboração de suas Diretivas Antecipadas de Vontade, no entanto, com a exigência de uma capacidade especial, denominada discernimento, a criança e o adolescente tornam-se pessoas habilitadas para prestar consentimento em relação à tratamento de saúde.

Logo, a utilização de uma Diretiva Antecipada de Vontade por criança ou adolescente, tem por fundamento a dignidade da pessoa humana, consagrada nos mais importantes documentos internacionais e no ordenamento jurídico brasileiro, que não permite tratar qualquer pessoa desumanamente ou degradante.

Em pesquisas à jurisprudência pátria, além dos poucos resultados encontrados sobre as Diretivas Antecipadas de Vontade aplicadas no contexto geral, não se verificou julgados que abordem a dispensa de tratamentos por crianças e adolescentes em estado de terminalidade, no entanto, em alguns países, é possível verificar casos em que a vontade do menor aliado ao discernimento, foi considerada para a dispensa de tratamentos. 
Um dos casos refere-se à Reece Puddington, um menino inglês de II anos, diagnosticado em 2008 com neuroblastoma, um tipo de câncer que se desenvolve principalmente em crianças. Em 2010 houve uma melhora em seu quadro clínico, contudo, em 2012 os médicos revelaram que a enfermidade havia evoluído e se espalhado para o fígado. $\mathrm{O}$ menino manifestou em suas redes sociais o desejo de interromper o tratamento e revelou que apesar do desejo de sua família em continuar com as terapias, foi apoiado em sua decisão, sucumbindo à doença no ano de 2014, conforme matéria escrita por Willians (2014).

No caso em questão, observa-se o fato de a família ter apoiado a criança em sua vontade de não mais prolongar a vida de maneira artificial, poupando-lhe o sofrimento que os efeitos colaterais do tratamento lhe causavam.

Assim, diante de uma situação semelhante, a participação e apoio da família não perdem o caráter de essencialidade, considerando que o momento no qual o filho se encontra enfermo é extremamente delicado para todos do convívio familiar, contudo, a tomada de decisões necessita de ponderação, devido à progressiva autonomia conquistada pelos menores, primordialmente se restar verificado o discernimento da criança e do adolescente para compreender a condição de saúde na qual se encontra, de forma que sejam evitados tratamentos que causem sofrimentos desnecessários e que não contribuam em nada para a manutenção de uma vida digna.

\section{CONSIDERAÇÕES FINAIS}

Como elucidado ao longo deste estudo, as Diretivas Antecipadas de vontade, apesar de ser um instituto pouco conhecido, é um instrumento que visa resguardar direitos fundamentais, de modo a que estes não sejam violados, uma vez que sua essência está pautada na qualidade de vida de pacientes terminais. Ao garantir a descontinuidade dos esforços terapêuticos ineficazes e prevendo a manutenção dos cuidados paliativos, reforçam a importância da dignidade no processo, morte, assim como durante a existência da pessoa humana.

É certo que devido à complexidade do tema apresentado, pode-se abrir uma pluralidade de perspectivas e discussões, pois, o assunto morte, por si só, já se apresenta na sociedade como um grande tabu a ser enfrentado e de certa forma superado, haja vista tratar-se de um processo natural irremediável, ao qual todos estão sujeitos.

Quanto à possibilidade da criança e do adolescente recusar tratamentos médicos, é reconhecido ao paciente que possua discernimento necessário, o direito de se se autodeterminar em questões que dizem respeito à sua existência, vez que é ele o titular do direito personalíssimo, 
o que importa em considerar sua anuência para a realização de determinados procedimentos terapêuticos, em respeito à sua dignidade.

Ademais, o exercício da autonomia implica riscos a qualquer pessoa, não se tratando este breve estudo de uma possibilidade desmedida de autonomia em toda e qualquer situação, de forma que o princípio do melhor interesse não deve ser confundido com o atendimento a todo e qualquer desejo da criança ou do adolescente, uma vez que, o poder familiar continua sendo exercido pelos pais, mas visto sob o prisma da dignidade da pessoa humana, deve ser aplicado com vistas a não anular o protagonismo dos filhos, sobretudo, quando se tratar de direito existencial.

A verificação de como se aplicará essa possibilidade só poderá ser feita no caso concreto, contudo, o que se busca é o equilíbrio nas relações familiares, de forma que diante de tal situação, a proteção das reais necessidades da criança e do adolescente sejam tomadas como ponto crucial da discussão, pois se o viver dignamente se mostrar inviável diante da situação de terminalidade, não se deve zelar a qualquer custo pela prorrogação da vida, já que a morte em determinadas situações também pressupõe o respeito à dignidade.

Deste modo, o presente trabalho ao suscitar tal discussão, não propõe uma solução concreta para as situações levantadas, busca, no entanto, fomentar a reflexão dos leitores e propor novas discussões, com o objetivo de que ocorram modificações capazes de satisfazer os anseios daqueles considerados vulneráveis.

\section{REFERÊNCIAS}

BARROS, Guilherme Freire de Melo. Direito da Criança e do Adolescente. 7. $\stackrel{a}{\text { ed. Bahia: }}$ JuspodiVm, 2018.

BEAUCHAMP, Tom L; CHILDRESS, James F. Princípios de Ética Biomédica. São Paulo:

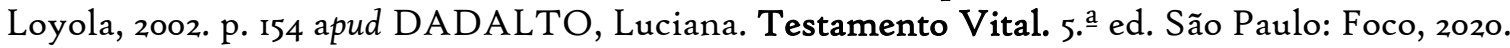

BELDA, Rosa Maria; BERMEJO, José Carlos. Testamento Vital: Diálogo sobre a vida, a morte e a liberdade. São Paulo: Loyola, 2015.

BRASIL. Constituição (1988). Constituição Da República Federativa do Brasil de 1988. Brasília, DF: Presidência da República. Disponível 〈http://www.planalto.gov.br/ccivil_03/Constituicao/ Constituiçao.htm〉. Acesso em: 7 de setembro de 2020 .

BRASIL. Lei n.o 8.069, de I3 de julho de 1990. Dispõe sobre o Estatuto da Criança e do Adolescente e dá outras providências. Diário Oficial da República Federativa do Brasil, Brasília, DF, ı6 de julho de $\quad$ 1990. Disponível em: < http://www.planalto.gov.br/ccivil_03/Constituicao/Constituicao.htm>. Acesso em: 27 de setembro de 2020 . 
BRASIL. Lei n.o 10.406, de ro de janeiro de 2002. Institui Código Civil. Disponível em: 〈http://www.planalto.gov.br/ccivil_03/leis/2002/10406.htm〉.

Acesso em 22 de agosto de 2020.

BRASIL. Tribunal de Justiça do Rio Grande do Sul. Agravo de Instrumento n. 70065995078. Primeira Câmara Cível. Relator: Sérgio Luiz Grassi Beck. Santa Catarina, RS, 3 de setembro de 2015. Disponível em: <https://www.tjrs.jus.br/novo/buscassolr/?aba =jurisprudencia\&q=Agravo + de + Instrumento $+\mathrm{N} \% \mathrm{C} 2 \% \mathrm{BA}+70065995078 \&$ conteudo_bus $\mathrm{ca}=$ documento_text $>$. Acesso em: 7 de novembro de 2020.

BRASIL. Ministério Público Federal. Ação Civil Pública n. 200014809-3014809-3. Sentença, I4. Vara Federal, Juiz Substituto: Roberto Luis Luchi Demo. Brasília, DF. or de dezembro de 2015. Disponível em: < https://www.conjur.com.br/dl/sentenca-resolucao-cfm-180596.pdf >. Acesso em: 7 de novembro de 2020 .

CABRAL, Hildeliza Lacerda Tinoco Boechat. Consentimento Informado no Exercício da Medicina e Tutela dos Direitos Existenciais: Uma Visão Interdisciplinar, Direito e Medicina. $2^{\underline{a}}$ ed. Curitiba: Appris, 2018.

CARDOSO, Juraciara Vieira. Eutanásia, Distanásia e Ortotanásia: O tempo Certo da Morte Digna. Belo Horizonte: Mandamentos, zoro.

CONINCK, Beatriz Diana Bauermann. Diretivas antecipadas de vontade e o direito de morrer com dignidade. Joaçaba: Unoesc, 2017.

CONSELHO DA JUSTIÇA FEDERAL. Jornadas de direito civil I, III, IV e V. Enunciados Aprovados. Enunciado n. ${ }^{\mathrm{o}}$ 138, aprovado na III Jornada de Direito Civil. Coordenador Científico: Ministro Ruy Rosado de Aguiar Júnior. Brasília: Centro de Estudos Judiciários, 2012. Disponível em: 〈https://www.cjf.jus.br/cjf/corregedoria-da-justica-federal/centro-de-estudos-judiciariosI/publicacoes-I/jornadas-cej/EnunciadosAprovados-Jornadas-I345.pdf>. Acesso em: il de novembro de 2020 .

CONSELHO FEDERAL DE MEDICINA. Resolução CFM no r.805/2006. Brasília, 28 de novembro de 2006. Disponível em: 〈http://www.portalmedico.org.br/resolucoes/cfm/2006/1805_2006.htm>. Acesso em: 27 de agosto de 2020 .

CONSELHO FEDERAL DE MEDICINA. Resolução CFM n.o 1.995/2012. Brasília, 3 I de agosto de 2012. Disponível em: 〈http://www.portalmedico.org br/resoluções/cfm/2012/1995_2012. Pdf >. Acesso em: 27 de agosto de 2020 .

CONSElHO FEDERAL DE MEDICINA. Código de Ética Médica: Resolução CFM no 2.217/2018, modificada pelas Resoluções CFM no 2.222/2018 e 2.226/2019. Brasília, 27 de setembro de 2018. Disponível em: 〈https://sistemas.cfm.org.br/normas/visualizar/resolucoes/BR/2018/2217〉. Acesso em: 27 de agosto de 2020 .

CONSELHO FEDERAL DE MEDICINA. Resolução CFM no 2.232/2019. Brasília, i6 de setembro de 2019 . Disponível em: 
https://sistemas.cfm.org.br/normas/visualizar/resolucoes/BR/2019/2232 >. Acesso em: $27 \mathrm{de}$ agosto de 2020 .

CONSELHO NACIONAL DOS DIREITOS DA CRIANÇA E DO ADOLESCENTE. Resolução CONANDA no 4r/1995. Brasília, 13 de outubro de 1995. Disponível em: 〈https://www.gov.br/mdh/pt-br/acesso-a-informacao/participacao-social/conselho-nacionaldos-direitos-da-crianca-e-do-adolescenteconanda/resolucoes/resolucoes-I-a-99.pdf $>$. Acesso em: Io de novembro de 2020 .

DADALTO, Luciana. Testamento Vital. $5^{\underline{a}}$ ed. São Paulo: Foco, 2020.

DECLARAÇÃO DOS DIREITOS DA CRIANÇA. Adotada e proclamada pela Assembleia das Nações Unidas, 20 de novembro de 1959. Disponível em: 〈http://www.direitoshumanos.usp.br/index.php/Crian\% $\mathrm{C}_{3} \% \mathrm{~A} 7 \mathrm{a} /$ declaracao-dos-direitos-dacrianca.html>. Acesso em: 20 de outubro de 2020.

DECLARAÇÃO UNIVERSAL DOS DIREITOS HUMANOS. Adotada e proclamada pela Assembleia Geral das Nações Unidas, io de dezembro de 1948. Disponível em: $\langle$ https://unric.org/pt/declaracao-universal-dos-direitos-humanos/ >. Acesso em: 20 de outubro de 2020 .

DIAS, Maria Berenice. Manual de Direito das Famílias. ıo ${ }^{\mathrm{a}}$ ed. São Paulo: Revista dos Tribunais, 2015.

DONIDA, Alcione Maria Araújo. Diretivas antecipadas de vontade e sua configuração no ordenamento jurídico brasileiro. Recife: DeVry, 2016.

Ehle, Gessika Adriana; RODRIGUES, Nina Tricia Disconzi. As Diretivas Antecipadas de Vontade em Tempos de Sociedade em Rede: Uma Análise da Lei Uruguaia no 18.473/2009 em Face do Direito Brasileiro. Florianópolis: CONPEDI, 2016. Disponível em: 〈http://conpedi.danilolr.info/publicacoes/910506b2/d4404fdp/G7iplzW toG577NJ2.pdf:>.

Acesso em: 24 de outubro de 2020.

FARIAS, Cristiano Chaves de; ROSENVALD, Nelson. Curso de Direito Civil: Contratos. $6^{\mathrm{a}}$ ed. Salvador: JusPodvim, 2016.

FRANÇA, Genival Veloso de. Direito Médico. $12^{\underline{a}}$ ed. Rio de Janeiro: Forense, 2014.

GAGlianO, Pablo Stolze; FILHO, Rodolfo Pamplona. Novo Curso de Direito Civil: Parte Geral. Vol. I. I9 ${ }^{\underline{a}}$ ed. São Paulo: Saraiva, 2017.

GODINHO, Adriano Marteleto. Diretivas Antecipadas de Vontade: Testamento Vital, Mandato Duradouro e Sua Admissibilidade no Ordenamento Jurídico Brasileiro. Revista do Instituto do Direito Brasileiro, Ano I, no 2, p. 945-978, 2012. Disponível em: 〈https://www.cidp.pt/revistas/ridb/2012/02/2012_02_0945_0978.pdf >. Acesso em 23 de outubro de 2020.

GONÇALVES, Carlos Roberto. Direito Civil Brasileiro: Parte Geral. Vol. I. I5 ${ }^{\underline{a}}$ ed. São Paulo: Saraiva, 2017. 
JIMÉNEZ, Nicolás Pilar. A Convenção de Oviedo sobre Direitos Humanos e Biomedicina: a gênese parlamentar de um ambicioso projeto do Conselho da Europa. Diário dos Tribunais Gerais, (40), 1997. Disponível em: 〈https://revista.cortesgenerales.es/rcg/article/view/935〉. Acesso em: 20 de outubro de 2020 .

LIMA, Renata Mantovani; POLI, Leonardo Macedo; JOSÉ, Fernanda São. A Evolução Histórica dos Direitos da Criança e do Adolescente: da insignificância jurídica e social ao reconhecimento de direitos e garantias fundamentais. Revista Brasileira de Políticas Públicas. V. 7, n. 2. agosto, 2017. Disponível em: 〈https://www.publicacoesacademicas.uniceub.br/RBPP/article/view/4796〉. Acesso em: or de novembro de 2020 .

LIPPMANN, Ernesto. Testamento Vital: O Direito à Dignidade. São Paulo: Matrix, 2013.

MABTUM, Matheus Massaro; MARCHETTO, Patrícia Borba. O Debate Bioético e Jurídico Sobre as Diretivas Antecipadas de Vontade. Iํe ed. São Paulo: Cultura Acadêmica, 2015.

MADALENO, Rolf. Direito de Família. $7^{\underline{a}}$ ed. Rio de Janeiro: Forense, 2017.

MARQUES, Ana Amélia Fernandes. Avanços e Limites do Estatuto da Criança e do Adolescente no Brasil: Uma Análise à Luz dos Princípios da Prioridade Absoluta e da Proteção Integral à Criança e ao Adolescente. Dissertação (Mestrado em Ciência Jurídica) - Universidade do Vale do Itajaí. Santa Catarina, 2orl. Disponível em:< http://siaibibor.univali.br/pdf/Ana\%2oAmelia\%2oFernandes\%20Marques.pdf $>$. Acesso em: 07 de novembro de 2020 .

MORAES, Maria Celina Bodin. Na medida da pessoa humana. Estudos de direito civil constitucional. Rio de Janeiro: Renovar, 2016 apud LINS, Ana Paola de Castro. O Exercício Da Autonomia Existencial Do Adolescente Em Processo De Hormonioterapia. Dissertação (Mestrado Acadêmico) Universidade de Fortaleza. Programa de Mestrado em Direito Constitucional, Fortaleza, 2017.

NADER, Paulo. Curso de Direito Civil: Parte Geral. Vol. I. II ${ }^{\mathrm{a}}$ ed. Rio de Janeiro: Forense, 2018.

NUNES, RUI. Diretivas antecipadas de vontade. Brasília, DF: CFM/ Faculdade de Medicina da Universidade do Porto, 2016.

ORGANIZAÇÃO MUNDIAL DE SAÚDE apud MATSUMOTO, Dalva Yukie. et al. Manual de Cuidados Paliativos/Academia Nacional de Cuidados Paliativos. $2^{\underline{a}}$ ed. Rio de Janeiro: Diagraphic, 2012.

PENALVA, Luciana Dadalto. As Contribuições da Experiência Estrangeira Para o Debate Acerca da Legitimidade do Testamento Vital no Ordenamento Jurídico Brasileiro. Anais do XVII Congresso Nacional do COMPEDI. Brasília, 2008. Disponível em: < http://conversandocomoprofessor.com.br/artigos/arquivos/testamento_vital__contribuicao.pdf >. Acesso em: 2I de outubro de 2020.

PENAlVA, Luciana Dadalto. Declaração Prévia De Vontade Do Paciente Terminal. Dissertação (Mestrado Acadêmico) Pontifícia Universidade Católica de Minas Gerais, programa de PósGraduação em Direito. Belo Horizonte, 2009. 
PEREIRA, Luciana Mendes. Testamento Vital: À Luz do Direito e Análise do Discurso. Curitiba: Juruá, 2018.

PRODANOV, Cleber Cristiano; FREITAS, Ernani César de. Metodologia do Trabalho Científico: Métodos e Técnicas da Pesquisa e do Trabalho Acadêmico. $2^{\underline{a}}$ ed. Novo Hamburgo: Editora Freevale, 2013.

PROVIN, Alan Felipe; GARCIA, Denise Schmitt Siqueira. Diretivas antecipadas de vontade e o princípio da dignidade da pessoa humana na hora da morte. Revista Eletrônica de Iniciação Científica. Itajaí, Centro de Ciências Sociais e Jurídicas da UNIVALI. V. 4, n. 4, p. 13-35, $4^{\underline{O}}$ Trimestre de 2013. Disponível em: 〈www.univali.br/ricc〉. Acesso em: 02 de novembro de 2020.

SENADO FEDERAL. Projeto de Lei n ${ }^{\circ}$ 149/2018: Direito Civil social/saúde. Brasília, o3 de abril de 2018. Disponível em: <https://legis.senado.leg.br/sdleggetter/documento? $\mathrm{dm}=7653326 \& \mathrm{ts}=1600968441794 \&$ disposition $=$ inline $>$. Acesso em: ${ }_{12} \mathrm{de}$ setembro de 2020 .

SENADO FEDERAL. Projeto de Lei n ${ }^{\circ}$ 267/2018: Social/Direitos humanos. Brasília, 29 de maio de 2or8. Disponível em:< https://legis.senado.leg.br/sdleggetter $/$ documento? $\mathrm{dm}=7737732 \& \mathrm{ts}=1594017158737 \&$ disposition $=$ inline $>$. Acesso em: 12 de setembro de 2020 .

TEIXEIRA, Ana Carolina Brochado; KONDER, Carlos Nelson. Crianças e Adolescentes na Condição de Pacientes Médicos: Desafios da Ponderação Entre Autonomia e Vulnerabilidade. Pensar, Fortaleza, V. 2I, n. I, p. 70-93, jan./abr. 2016. Disponível em: $\langle$ https://doi.org/ro.5020/10.5020/2317-2150.2016.v2Inip70〉. Acesso em: io de novembro de 2020.

TRAVESSONI, Alexandre. Kant e o Direito: Immanuel Kant. Belo Horizonte: Mandamentos, 2009.

WILLIAMS, Amanda. 'Mum 's letting me go': With breathtaking dignity, bucket-list boy, Ir, who has been battling cancer for six years reveals he and family have taken heartbreaking decision to stop life-prolonging treatment. Daily mail, i8 de fevereiro de 2014. News. Disponível em:< https://www.dailymail.co.uk/news/article-2562208/Mums-letting-Boy-battling-cancer-sixyears-revealed-online-blog-family-heartbreaking-decision-stop-treatment-prolong-life.html>. Acesso em: 08 de novembro de 2020 . 